\title{
PAPA, S. M. DE B.I. Prática pedagógica emancipatória: o profes- sor reflexivo em processo de mudança - um exercício em análise crítica do discurso. São Carlos: Pedro \& João Editores, 2008, 215 págs.
}

\section{Resenhado por José Ribamar Lopes Batista Júnior ${ }^{2}$}

Escrito por Solange Papa, professora no curso de Letras da Universidade do Estado de Mato Grosso (UNEMAT) e no Programa de Mestrado em Linguagens, junto à Universidade Federal do Mato Grosso (UFMT), com pesquisas sobre formação de professores/as de Língua Estrangeira (LE) e sobre contextos de exclusão social, este livro é resultado de sua pesquisa de doutoramento intitulada "O professor reflexivo em processo de mudança na sala de aula de LE: caminhos para a auto-emancipação e transformação social" e concluída em 2005, sob orientação da Profa. Dra. Leila Bárbara.

$\mathrm{Na}$ Introdução, de forma breve, Papa apresenta o contexto da pesquisa (um estudo de caso etnográfico), os/as participantes e o arcabouço teórico-metodológico utilizado, bem como descreve a estrutura do livro (que contém três partes - teórica, metodológica e analítica). Seu trabalho está voltado para os aspectos linguísticos, socioculturais, políticos e ideológicos, a fim de "compreender se as práticas discursivas de uma professora reflexiva revelam algum propósito emancipatório, bem como conhecer as implicações da sua prática docente para o processo de formação do educador de LE” (p. 26).

Na primeira parte, dedicada aos fundamentos teóricos do livro, há três capítulos. Em "Emancipação social e prática discursiva reflexiva", a autora, com base na filosofia bhaskariana, trata da teoria crítica

2. Mestre e Doutorando pelo Programa de Pós-Graduação em Linguística da (UnB) 
sobre emancipação e transformação social. Nesse capítulo, mostra a relevância dessa teoria para seu objeto de estudo, possibilitando, assim, "compreender as ligações existentes entre a sala de aula e os fatores sociais, políticos e ideológicos, que permeiam toda a rede de relações na escola e na sala de aula, e, assim, propor a abertura de novos caminhos para a emancipação e transformação social (p. 25-26).

Ainda nesse capítulo, a autora discute o ensino de inglês e a postura do/a professor/a para a emancipação e criticidade de ambos/as, professores/as e alunos/as. Vale ressaltar que essa visão emancipatória no ensino não é exclusiva para o ensino de LE. Em qualquer área do ensino-aprendizagem "o educador crítico deve ser um agente político de mudança, inserir-se de forma crítica na realidade social onde trabalha, constituindo-se, portanto, como agente fortalecedor para lutar a favor da transformação social” (Rajagopalan, 2003, p. 111-112 apud Papa, 2008, p. 29-30).

Em seguida, Papa discorre sobre a formação reflexiva do/a professor/a de línguas, enfatizando a importância da educação contínua do/a professor/a de LE e que as práticas reflexivas não podem ser reduzidas apenas aos problemas pedagógicos, restritos à sala de aula. E isso, como atesta Papa, com base nos estudos de Giroux (1997), representa dificuldades para o/a professor/a reflexivo/a ante as esferas sociais mais amplas. Para essa formação reflexiva, é preciso que os docentes relacionem os trabalhos de sala de aula com os problemas sociais da escola e da comunidade, por exemplo. Além disso, faz-se necessário um trabalho coletivo, comprometido e engajado, entre educadores/as e pesquisadores/as das universidades, no intuito de desenvolver ações concretas para a emancipação e transformação social de todos/as os/as envolvidos/as no processo de ensino-aprendizagem.

A transformação deve acontecer, segundo a autora, no mundo da consciência e, principalmente, da prática. Por isso, leva-se em consideração a linguagem como instrumento de "produção, manutenção e mudança das relações sociais de poder" (Fairclough, 1989). O discurso, dentro das práticas sociais em que os indivíduos atuam, concorre para a 
manutenção ou a transformação de visões de mundo, que tem influência na construção de identidades. Assim, por meio do estudo do discurso, é possível compreender as práticas sociais de um/a professor/a reflexivo/a, bem como conhecê-lo/a, tendo acesso a crenças, valores e identidade.

No segundo capítulo, intitulada "Gramática Sistêmico-Funcional - GSF”, a autora explica os preceitos dessa corrente teórica. De acordo com Halliday (1994), a GSF é "funcional em sua interpretação dos textos, do sistema e dos elementos da estrutura linguística. Ela é voltada para descrição da linguagem como uso em determinado contexto, pois entende que é o "uso da linguagem que molda o sistema" (Silva, 2009, p. 24). E por entender que a linguagem se organiza em torno de um propósito, o autor estabelece para os componentes funcionais da língua três metafunções, em que por meio delas podemos identificar como o discurso está organizado: i) metafunção interpessoal (expressa os papéis e as atitudes dos/as participantes de determinada interação; ii) metafunção ideacional (o uso da língua como representação, relacionado ao mundo exterior e ao mundo interior, inclusive a pensamentos, crenças e sentimentos); iii) metafunção textual (relacionada à variável de registro e se expressa por meio da ordem dos constituintes da oração, que dá significado à mensagem).

No terceiro capítulo "Análise Crítica do Discurso" (também conhecida como Análise de Discurso Crítica, doravante ADC) apresenta os aspectos teóricos metodológicos da Análise de Discurso, com base na vertente inglesa, desenvolvida por Norman Fairclough (1989, 1995, 2001, 2003), definida como um campo de pesquisa transdisciplinar, alicerçada na Teoria Social Crítica - TSC. Papa faz uma explanação dos pressupostos teóricos da ADC desde a concepção do modelo tridimensional (Fairclough, 2001) até a convergência entre a GSF e a ADC (Fairclough, 2003), duas correntes linguísticas que contribuíram, significativamente, para o objetivo principal da pesquisa: compreender as práticas discursivo-reflexivas de uma professora de LE (identificada como Ivana), seus diferentes modos de enxergar e sentir a realidade e o mundo. 
Para a compreensão do discurso em relação aos elementos da prática social, Chouliaraki e Fairclough (1999) orientam aos/ às pesquisadores/as a combinação dos estudos discursivos com a vivência em campo, por meio do método etnográfico. Nesse sentido, a autora, na segunda parte do livro, (subdividida em quatro capítulos), apresenta a metodologia utilizada, descreve o contexto de pesquisa, os/ as participantes (professora, alunos/as e a própria pesquisadora) e suas experiências. Além disso, relata o processo de entrada no campo, cita os instrumentos (entrevistas e gravação de aulas) para a coleta dos dados.

Ao utilizar a etnografia, a pesquisadora faz uma escolha adequada para sua pesquisa, visto que trabalhar com essa abordagem de pesquisa qualitativa lhe permitiria uma compreensão holística do contexto social, bem como dos/as participantes e respectivas ações. Entretanto, como o objetivo da pesquisa era compreender a questão da emancipação e transformação social, haveria a necessidade de mais instrumentos de coleta de dados, tais como narrativas (das histórias de vida), notas de campos, diários reflexivos e participação mais efetiva em campo. No último capítulo da segunda parte, a autora explicita quais as categorias de análise utilizadas para compreender o contexto social da professora Ivana, assim como revela as experiências discursivas na/sobre a sala de aula.

A terceira e última parte, intitulada "Fundamentos analíticos", está dividida em três capítulos, e consiste na apresentação dos resultados da pesquisa. Os resultados mostram que a professora pesquisada é comprometida com a escola onde leciona; tem mais afinidade com os alunos do período noturno, valoriza a cultura afro-descendente, possui conhecimento teórico acerca da formação do educador reflexivo e procura (re)construir sua prática docente com base na reflexão.

Além disso, Papa mostra, por meio da análise discursiva e de sua experiência como pesquisadora, que é em sala de aula que a professora constrói as características da identidade docente emancipatória; que no convívio com os/as demais atores sociais envolvidos suas práticas discursivo-reflexivas emergem, garantindo sua atuação como educadora 
de LE. Ao final, apresenta um modelo do processo de formação da prática discursivo-reflexiva que envolve três níveis: i) estrutura interna (valores, crenças, sentimentos e identidade); ii) contexto de relações microssociais (contexto de sala de aula) e iii) contexto das relações macrossociais (contextos sociocultural, político e ideológico). Dessa forma:

as mudanças devem ocorrer primeiramente, no nível de estrutura interna dos participantes envolvidos no projeto emancipatório e de transformação social, bem como devem estar relacionadas com a questão de valores, sentimentos, atitudes e identidade, envolvendo não apenas a 'consciência reflexiva' do educador, mas, sobretudo, a ação, num processo dialético constante (Papa, 2004, Mimeo/LAEL-PUC/SP apud Papa, 2008, p. 189)

Por fim, em "Conclusões" os resultados das análises são retomados e a autora se auto-avalia enquanto educadora e pesquisadora. O livro traz a contribuição de ilustrar de como os dados etnográficos, os textos, as práticas de análise em ADC, a prática da investigação e interpretação dos dados como um todo incorporaram-se ao conhecimento de mundo da pesquisadora, e que tal incorporação é recomendada no sentido de que pode subsidiar a reflexividade e a mudança na sua atitude e na forma de conduzir o fazer pedagógico. Também por inspirar outros/as investigadores/as a buscar nas investigações de suas próprias práticas, os elementos para a mudança social. E mais, o livro "abre caminhos para a construção de um projeto emancipatório e de transformação social” (Papa, 2008, p. 201), por meio da própria crítica.

\section{Referências bibliográficas}

chouliaraki, L. \& Fairclough, N. Discourse in late modernity. Rethinking critical discourse analysis. Edinburgh: Edinburgh University Press, 1999.

Fairclough, N. Analysing discourse. Routledge: Taylor \& Francis Group. London and New York, 2003. 
. Discurso e mudança social. Coord. trad. revisão e prefácio à ed. brasileira Izabel Magalhães. Brasília: Editora Universidade de Brasília, 2001.

. Critical discourse analysis: the critical study of language. London: Logman, 1995.

. Language and power. London: Longman, 1989.

Giroux, H. Os professores como intelectuais: rumo a uma pedagogia crítica da aprendizagem. Porto Alegre: Artes Médicas, 1997.

Halliday, M. An introduction to functional Grammar. 2 ed. London: Edward Arnold, 1994.

Papa, S. M. DE B.I. Realismo crítico e a prática pedagógica emancipatória. Mimeo. Lael/PUC/SP, 2004.

Rajagopalan, K. Por uma linguística crítica: linguagem, identidade e a questão ética. São Paulo: Parábola Editorial, 2003.

Silva, L. R. da. As identidades femininas: discurso e letramento no contexto escolar. 2008. 338 p. Tese de Doutorado em Linguística (inédita). Brasília: UnB, 2008.

Recebido em: maio de 2009 Aprovado em: setembro de 2009 ribamar_junior16@yahoo.com.br 